\title{
Appraisals of Wildlife During Restorative Opportunities in Local Natural Settings
}

\author{
Maria Johansson ${ }^{1 *}$, Anders Flykt ${ }^{2}$, Jens Frank ${ }^{3}$ and Terry Hartig 4,5 \\ ${ }^{1}$ Environmental Psychology, Department of Architecture and Built Environment, Lund University, Lund, Sweden, \\ ${ }^{2}$ Department of Psychology and Social Work, Mid Sweden University, Östersund, Sweden, ${ }^{3}$ Grimsö \\ Wildlife Research Station, Department of Ecology, Swedish University of Agricultural Sciences, Riddarhyttan, Sweden, \\ ${ }^{4}$ Institute for Housing and Urban Research, Uppsala University, Uppsala, Sweden, ${ }^{5}$ Department of Psychology, Uppsala \\ University, Uppsala, Sweden
}

\section{OPEN ACCESS}

Edited by:

Martin F. Quaas,

Leipzig University, Germany

Reviewed by:

Joel Methorst,

Helmut Schmidt University, Germany

Andreea Nita,

University of Bucharest, Romania

*Correspondence:

Maria Johansson

maria.johansson@mpe.Ith.se

Specialty section:

This article was submitted to

Conservation and Restoration

Ecology,

a section of the journal

Frontiers in Environmental Science

Received: 30 November 2020

Accepted: 06 April 2021

Published: 03 May 2021

Citation:

Johansson M, Flykt A, Frank J and Hartig T (2021) Appraisals of Wildlife

During Restorative Opportunities

in Local Natural Settings.

Front. Environ. Sci. 9:635757.

doi: $10.3389 /$ fenvs.2021.635757
Many call for a broad approach to valuation of nature's contribution to people, one that provides a contextualized understanding of what may be experienced as a value in different cultures, groups and settings. In the present paper we address contributions of nature to psychological well-being as realized through restorative processes during encounters with wildlife. Although restorative benefits of nature experience have received much consideration, sparse attention has been given to the role of the presence or absence of different animals in the settings investigated. The presence of a liked species may increase appreciation for and engagement with a natural setting, but fear of encountering some species may counter the desire to visit a setting with otherwise high restorative quality. This paper proposes a psychological framework for understanding how wildlife may contribute to or hinder people's opportunities to restore in local natural settings. The framework addresses the transaction between the individual and their surroundings, making use of an appraisal theory of emotion and theories about the restorative benefits of nature experience. We focus upon encounters in landscapes shared by humans and wildlife, and we elaborate on our reasoning with scenarios from Sweden involving local people's appraisal of wolves and roe deer. An integrated understanding of the psychological processes at work would facilitate communication and decision-making about the contribution of wildlife in nature conservation and management.

Keywords: attention restoration, emotional appraisal, recreation motives, stress recovery, wildlife

\section{INTRODUCTION}

After decades of decline, populations of large carnivores and other threatened species of wildlife have begun to recover in Europe. Reasons for this development include hunting regulations, conservation efforts, and changes in land use, such as the abandonment of agricultural fields (Apollonio et al., 2010; Chapron et al., 2014). Such developments count as ecological successes. Together with survival of the species and increased chances that they regain functional significance in local ecologies, the increasing abundance of these animals means that people can more frequently interact with them in the landscapes that they share (Penteriani et al., 2016). Thus, at the same time 
that wildlife management, environmental regulations and other forms of protective action have prevented the extinction of species, they have also prevented the extinction of experiences that people can have with those species (Pyle, 1993; Soga and Gaston, 2016).

Yet, the experiences people may have with recovering species such as wolves can differ widely, and the social consequences of some such human-wildlife interactions have become the focus of intense debate between groups. Defined in terms of, for example, rural versus urban residence (Johansson et al., 2016b), different livelihoods and life-styles (e.g., farming and animal husbandry, hunting with dogs; Eklund et al., 2020; Eriksson et al., 2020), and value orientations and attitudes (Sponarski et al., 2013). These groups can hold widely divergent opinions about the animal species in question as well as the management of them. This means that the debate about human-wildlife interaction involves not only perceived negative impacts of particular animals as threats to personal safety, livelihood and lifestyle, but also infected social conflicts between local populations and other stakeholders, including the governmental authorities charged with managing wildlife (Redpath et al., 2013). The intensity of the debate increases with a perceived lack of understanding of the psychosocial consequences of the presence of particular animals and of the burden that wildlife management measures can impose on individuals and the collective, particularly in rural areas (Eklund et al., 2020; Sjölander-Lindqvist et al., 2015).

This debate contrasts starkly with movement toward scientific consensus on the positive values of nature experience for human health and subjective well-being (e.g., Bratman et al., 2019). However, the research behind this emerging consensus has largely focused on the experience of people in the urban populations of wealthy, industrialized countries (e.g., Hartig et al., 2014). It has also typically represented what people take to be "nature" in a limited set of contexts, with a particular emphasis on recreational activities (Hartig et al., 2011). At the same time, it has represented "nature" in a coarse manner, for example as green space, without attending to more specific ecological characteristics of the natural environment, including the particulars of the funga, flora and fauna in a given setting (e.g., Velarde et al., 2007; Markevych et al., 2017; Marselle et al., 2021).

Recognizing this latter limitation of the research on nature and health, some researchers have begun to study benefits of experiences with specific, ecologically relevant aspects of natural settings. ${ }^{1}$ For example, recent years have seen claims that parks and other greenspaces with higher levels of species diversity and abundance will engender more psychological benefits of relevance to health (e.g., Fuller et al., 2007; Cameron et al., 2020). However, the set of studies on beneficial encounters with biodiversity remains relatively limited in important respects. The

\footnotetext{
${ }^{1}$ The term "setting" ordinarily gets used in environmental psychology both to spatially and temporally delimit the environment and to more explicitly implicate the activity of humans as related to the specific features of the environment so delimited. We use the term "natural setting" throughout this paper to implicate the presence of a person or persons engaged in some activity or activities in a setting dominated by trees, vegetation, freely moving water and other seemingly natural features. For further discussion of such definitional issues in research on nature and health, see Hartig (2021; Hartig et al., 2011).
}

implications of the diversity and abundance of animals other than birds and butterflies have largely been neglected, and the focus has remained on experiences of urban residents within a recreational context (Jorgensen and Gobster, 2010). So, although such studies have addressed important knowledge gaps relevant to understanding the health values of encounters with wildlife, they have not directly addressed persistent concerns that fuel debates like those about the presence of wolves, deer, and other animals that some people see as hazards or pests and others see as highly valued components of the environment.

Although neglected in research on nature experience and health, the ambivalent feelings and attitudes evidenced by the parties to such debates have received much research attention in the field of human dimensions of wildlife (e.g., Decker et al., 2012). In this field, the concepts of nature and biodiversity translate into wildlife and specific animal species (e.g., Manfredo, 2008). Moreover, the empirical research is often situated in the urban-wildland interface or in rural areas, where residents have more frequent and different types of encounters with wildlife than those available to urban residents, and within a range of contexts that includes but is not limited to consumptive and non-consumptive recreational activities. The plethora of humanwildlife interactions as well as the species specific interactions in such contexts has been shown by social network analysis (Pătru-Stupariu et al., 2020). Human-wildlife interactions with different species can trigger both positive and negative feelings (Jacobs et al., 2014; Eriksson et al., 2020) and accompanying physiological responses (e.g., with bears, wolves, moose, and hares; Flykt et al., 2013). For some people, encounters with certain mammal and bird species may evoke awe and fascination, and an increasing abundance of such animals may therefore enhance the recreational quality of the local nature, attracting tourism income while also boosting residential satisfaction (e.g., Jorgensen et al., 2007). For other people, the same animal species may constrain recreational and residential quality, due to concerns about encounters (Kubo and Shoji, 2014). In other cases, people generally may show a high degree of consensus regarding the desirability - or undesirability - of a particular species. For example, in Scandinavia and elsewhere, a known abundance of ticks (Ixodes ricinus) causes people to limit their outdoor activities and take protective measures in certain areas (Slunge and Boman, 2018). Similarily, Nordström (2010) found that a high degree of exposure to floodwater mosquitoes (Aedes sticticus) and (Aedes vexans) was reliably associated with diminished psychological well-being in local residents. In attending to such phenomena, work in the field of human dimensions of wildlife offers a useful complement to research on the positive health values of "nature" and encounters with preferred, unthreatening expressions of biodiversity.

The non-material contribution of wildlife could be considered both as positive and negative, and be represented in a broad set of psychological well-being outcomes (Methorst et al., 2020). This paper supports further integration of research in environmental psychology, the psychology of emotion, conservation biology and human dimensions of wildlife by nuancing the understanding of psychological outcomes of increasing wildlife abundances in landscapes shared by people and wildlife across the urban-rural 
gradient. Our integration of this research adheres to the call from the International Panel for Biodiversity and Ecosystem Services for a broad approach to the valuation of "nature's contributions to people" that goes beyond economic cost - benefit analyses (Pascual et al., 2017). Importantly the research serves to provide a contextualized understanding of what may be experienced as a contribution of wildlife in different cultures, groups and settings (Díaz et al., 2018). Toward these ends, we propose a psychological framework for understanding how wildlife may contribute to or hinder people's opportunities for psychological restoration in local natural settings. We also offer a model of how people behave up to, during and after an encounter with wildlife.

In the following, then, we first briefly consider theory concerned with human-environment relations in general. Next, we outline the more specific theories about emotional appraisals and restorative experience that we draw on in characterizing the person's transaction with the environment in the encounter with wildlife. So prepared, we offer our integration of the theories and apply the model with some examples set in the Swedish context. In closing, we discuss our framework and model with a view to their use in understanding nature's contributions to people's health and wellbeing. An integrated understanding of the psychological processes at work should facilitate communication and decision-making about the contribution of wildlife in nature conservation and management.

\section{GENERAL THEORETICAL FRAMEWORK}

A general approach to understanding the values of animate and inanimate aspects of the natural environment refers to their implications for human health and well-being through processes of adaptation. This approach treats wildlife as an aspect of nature that can influence health and well-being via pathways in four broad domains (see Figure 1). Each of the domains includes known and unknown but potentially discoverable pathways by which wildlife can come to have implications for the given aspect of adaptation to the environment. Thus, the presence and activities of wildlife in the local environment can affect health and well-being, both negatively, by undermining adaptation (i.e., by causing harm) and positively, by supporting adaptation (i.e., by helping people to build and restore adaptive capacities and by reducing harm).

Figure 1 further indicates that pathways in one domain can relate to pathways in the other domains. Relations between pathways may be competitive, as when the presence and/or activities of a given animal evoke strong fear in a person (activating one or more pathways within the domain of causing harm) and so aggravate stress that a person seeks to escape while in the natural setting (disallowing the operation of one or more pathways in the domain of restoring capacities). Yet, pathways in the different domains may also show complementary relations over time, as when a person who knows a threatening animal may be encountered in the setting acquires the knowledge and behavioral skills needed to manage a potentially harmful encounter (pathways in the building capacities domain) and so can come to enjoy the presence of the animal in its natural habitat (enhancing the restorative quality of the setting). It follows that pathways in each of the domains can work to relate the presence and activity of wildlife to human health and well-being in diverse ways over widely varying spans of time, from the momentary to the total life course.

Although Figure 1 severely simplifies a complex reality, it closely resembles other models that have proven useful in organizing and guiding research in other areas within the natureand-health field. For one, it explicitly distinguishes between what actually exists in the environment and what the person comes to experience there; however, rather than more general representations of the environment, such as nature (Hartig et al., 2014; Bratman et al., 2019) and biodiversity (Marselle et al., 2021), our model starts from the wildlife that exists in the environment and the encounters that people may have with that wildlife. The organization of pathways into broad domains follows the example of Markevych et al. (2017), who addressed the positive effects of greenspace on health, and the example of Marselle et al. (2021), who addressed both positive and negative health effects of biodiversity. Our inclusion of a domain of pathways by which wildlife can cause harm follows the example of Marselle et al. (2021); however, in contrast to their example, our model acknowledges that wildlife can harm human health without any encounter taking place. It thus acknowledges that the presence and activity of wildlife can engage different pathways to health and well-being not only through the encounters that people have with the wildlife but also in ways that involve only some awareness of the possibility of an encounter or that are entirely outside of the awareness of the people affected. Finally, as in the presentation of these previous models, we acknowledge that the strength of an effect realized through a given pathway in any of the domains may depend on characteristics of the given context and of the people involved.

In theory, one or more pathways in all four of the domains could become engaged by a particular animal or species of animal in a given encounter and/or in repeated encounters over time. Also, these pathways could work within a broad range of contexts for wildlife encounters, from feeding birds outside one's home to tracking lions as a hunter to visiting a remote region as an ecotourist. Here, to simplify our presentation while also addressing issues of widespread concern, we narrow our focus to a smaller set of pathways and contexts. First, we focus on the operation of pathways within two domains, those of causing harm and restoring capacities, and we propose a psychological framework to understand how the presence of wildlife species may constrain or contribute to opportunities for restoration. Second, we focus on encounters that occur in local natural settings that people can access from their homes on a regular basis in daily life. In making this choice, we define the natural settings of interest not only in terms of their accessibility to people but also in terms of their status as ordinary habitat for the animals that those people could encounter. Thus, although we do not consider many other contexts of interest or health-relevant pathways that could become engaged with wildlife encounters, we nonetheless address a set of pressing issues that extend over relatively many people and animal populations in many places. Our presentation here thus has broad relevance. 


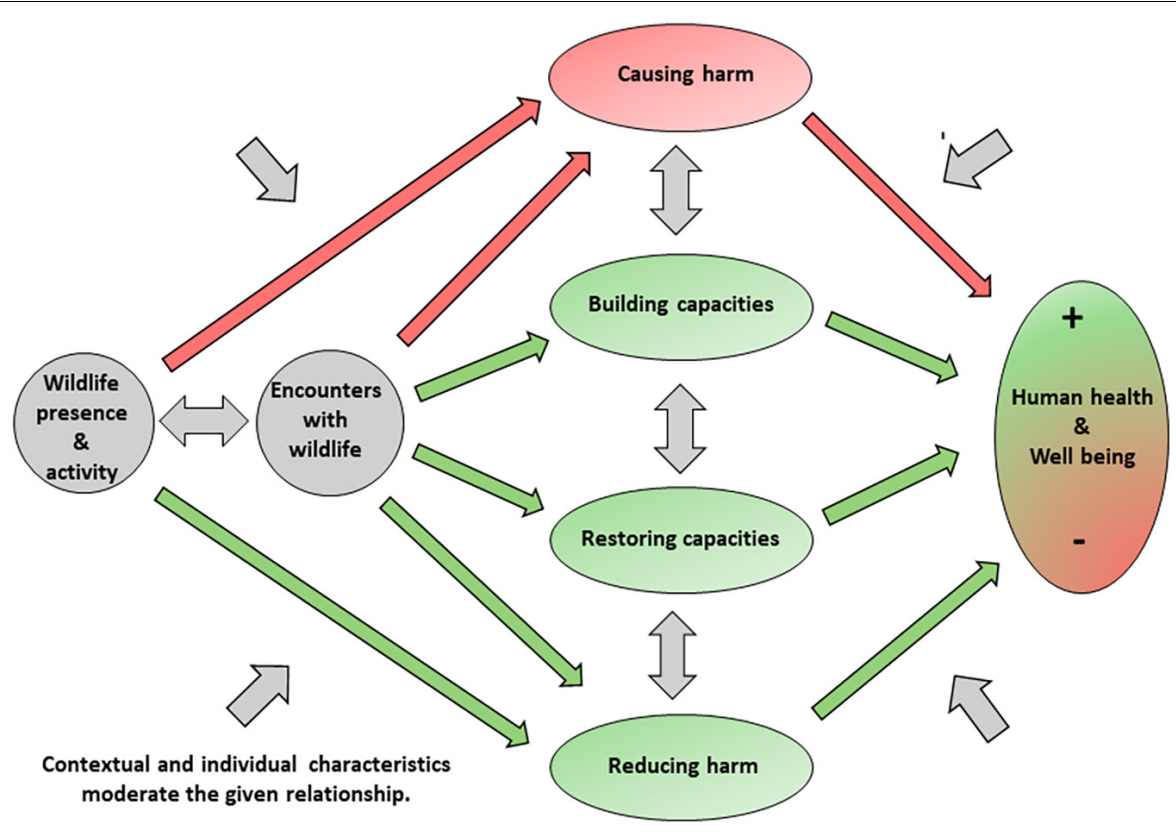

FIGURE 1 | A general conceptual model with domains of pathways through which the presence and activity of wildlife can come to have both positive and negative effects on human health and well-being. Some pathways do not run through encounters with wildlife, indicating that they may have effects by means outside the awareness of the people involved. Pathways in any one domain may influence and/or be influenced by pathways in any another domain, but for simplicity in the presentation only relationships between adjacent domains are shown. The vertical ordering of the pathway domains also serves to simplify the presentation; it does not imply a necessary logical order. As indicated by the gray arrows, the strength and direction of effects transmitted via pathways in any of the domains may depend on features of the context (e.g., everyday life in a rural residence versus a guided wildlife safari in an exotic location) and of the individual (e.g., age, gender, emotional disposition, work in animal husbandry versus wildlife conservation, and hunting experience). Adapted from Hartig et al. (2014); Markevych et al. (2017) and Marselle et al. (2021).

We see important reasons to focus here on pathways in the restoring capacities and causing harm domains. Restoration has long been recognized as an important motive for visits to natural areas in urbanized countries (e.g., Knopf, 1987; Home et al., 2012). Similarly, access to opportunities for restoration in natural settings figures prominently among those who own a second home in a rural area (Fransson and Hartig, 2010). For people who have their sole or primary residence in rural areas, both daily demands and restoration opportunities are situated in rural settings, and wildlife may figure in the demands they face as well as in their restoration opportunities, for good or ill. Furthermore, the pathways of the restoration and causing harm domains, such as stress recovery or threat of attack, will in this context ordinarily have implications for pathways in the other domains, as when a person decides whether or not to wind down from stressful work by taking a walk in a nearby natural setting (i.e., physical activity as a pathway to health and well-being through the capacity building domain) (e.g., Staats et al., 2003; Dzhambov et al., 2018).

When people actively seek restoration in a natural setting, wildlife presence may play into the restorative opportunities in one or more of three general stages in a restorative process: before a visit when choosing a suitable setting, during a visit while engaging with the setting, and after a visit through feedback that influences future setting choices based on the experience just had in given setting. In any one of these stages, the potential for restoration may compete with the potential for harm of some kind in determining the degree to which the person benefits from the experience. For example, a person may choose to go to a given setting specifically to experience wildlife, as when a bird watcher heads toward a site where a rare species has been reported, or a person may deliberately avoid a setting, as when a berry picker avoids a nearby forest because brown bears have been reported there. In this paper, we focus on restoration as it unfolds on site, as one or more people are engaged with the setting. We outline how the experienced presence of different wildlife species can work to sustain or undermine restoration a person has sought with a visit to a natural setting.

Why might different wildlife species trigger different psychological responses? Why might these responses differ between people? How might contextual factors work to amplify or soften responses? How do these various aspects of an encounter, taken together, play into the restoration that a person realizes during a nature experience? Here we draw on general and specific theories within psychology to address processes of approach and avoidance based on people's emotional appraisal of the presence of wildlife in relation to perceived opportunities or constraints for restoration in the natural setting. Within psychology, the interplay between the person and the surroundings gets described in terms of diverse, continuously ongoing psychological processes. As a general theory in environmental psychology, the Human-Environment Interaction (HEI) model (Küller, 1991) treats the outcome of this 
interplay as dependent upon the individual's integrated appraisal of the activity engaged in, the perception of the physical and social environmental contexts, and the characteristics of the individual (e.g., socio-demographic background, personality, emotional disposition toward and prior experience with given animal species). Applied to potential or actual encounters with wildlife, the HEI model indicates that the description of the psychological processes of interest would involve reference to characteristics of both the people and the animal(s) involved (Johansson et al., 2012a, 2016b). Further, the HEI model indicates that the psychological process description would attend to the specific behavioral context in which the person or people and the animal(s) meet - the respective activities they are engaged in (e.g., a person gathering berries; an adult animal feeding) - as well as physical and social aspects of the context (e.g., the person is alone but at a distance from a female bear with cubs in a place that affords little possibility for escape). In this latter regard, we recognize that the person or people involved may experience the animal(s) simply as features of the physical environment to observe, or as a kind of social partner with whom they interact. Thus, we acknowledge that the ways in which the animal(s) in question perceive and act toward the people involved (cf. Sahlén et al., 2015), are important aspects of the description of the psychological processes of interest; however, we focus here on the human responses.

\section{SPECIFIC THEORETICAL BACKGROUND}

Building on the model of pathways from nature to health and on the HEI model as a general theory in environmental psychology, we can draw on more specific theories to provide descriptions of interrelated psychological processes running through the encounters that people have with wildlife. In the following, we comment on approach-avoidance tendencies that people show in response to features of the environment, and briefly overview research on characteristics of the person and the animal that can influence a person's appraisals during an encounter. We outline the two areas of theorizing we integrate: on aspects of restorative experience as situated in natural settings, and on the particulars of ongoing emotional appraisal. We acknowledge the significance of the animal(s) own experience in the given encounter, but in the present account we will only refer to it insofar as it has relevance for the experience of the person or people involved.

\section{Approach - Avoidance and Environmental Features}

A person's behavior during the transaction with an environment involves basic approach and avoidance dimensions, with approach being linked to reward and incentives and avoidance being associated with concepts such as aversion, punishment and threat (cf., Carver, 2006; Elliot et al., 2013). Gray (1982) has suggested that different neurological systems underlie the behavioral activation system related to approach and the behavioral inhibition system related to avoidance. Some environmental stimuli tend to elicit different reactions in different people in terms of approach and avoidance, and this might be taken as a basis of personality (Gray, 1982). Recently, however, it has been argued that approach and avoidance processes are present and interact at several functional levels (e.g., Corr, 2013). This means that approach-avoidance tendencies do not conform rigidly to personality profiles but rather show inherent flexibility and plasticity. Even if approach and avoidance are based on different subcortical systems and affected by early learning, they could be expected to yield different degrees of approach and avoidance in different situations based on how these situations are appraised. In this view, situations are construed as sets of focal stimuli within a context. In other words, the context is assumed to comprise one important set of moderators of approach-avoidance tendencies and so of the play of subsequent psychological processes.

\section{Different People Have Different Appraisals of Different Wildlife Species}

Considering a particular animal in a given context, previous research has shown that it is likely to be differently appraised by different people. The literature on human dimensions of wildlife points to animal species characteristics, cultural factors, personal characteristics, and prior experiences of human-wildlife interactions (own or vicarious) as parameters that influence these appraisals.

Human appreciation and concern for animal species differ widely between and within taxa. The general order of preference across taxa seems to be (1) birds, (2) mammals, (3) amphibians, reptiles and fishes, and (4) invertebrates (Kellert, 1985; Kelly et al., 2016). In terms of conservation importance, the order of taxa is slightly different, but birds and mammals still have the top positions, with birds rated higher than mammals (Knegtering et al., 2002). Within a taxa, animal characteristics such as relative size and rarity seem to matter, with assessments of higher importance for conservation assigned to relatively large and rare (or vulnerable) species (e.g., Knegtering et al., 2002; Fischer et al., 2011). Aesthetically appealing characteristics are also associated with preference and assessments of the importance of their conservation among the public (Knight, 2008). Smith et al. (2012) relate aesthetic judgments to traits such as higher body-mass index and forward facing eyes (Fischer et al., 2011). Such bio-behavioral similarity, or human resemblance in appearance, behavior and social interaction, seems to be a factor in attractiveness (Serpell, 2004; Batt, 2009; Manesi et al., 2015).

Species that are considered as native species get relatively high assessments with regard to the acceptability of an increase in their population (Serpell, 2004; Fischer et al., 2011). In addition, appreciation seems to be positively associated with the perceived utility of the species, which also involves an economic valuation of the species. Serpell (2004) proposed a twodimensional structure of human attitudes toward animal species encompassing affect together with utility. Using a factor-analytic approach, Kellert (1985) found animal species categorized into "domestic animals," which were most preferred, followed by "attractive animals," while animals associated with property damage, animals associated with injury, and biting/stinging invertebrates were the least preferred. Expressions of negative 
affect toward wildlife have in particular been discussed in relation to the extent that the animals elicit fear responses and/or constitute threats to pets, human property and/or livelihood (Jacobs et al., 2012; Johansson et al., 2016a; Eklund et al., 2020). Ware et al. (1994) used a factor analytic approach to categorize self-reported fears of a global list of animal species into those labeled high predatory (e.g., tigers, alligators, bears, and wolves) and fear-relevant (e.g., eagles, lizards, slugs, and mice). Arrindell (2000) arrived at a more comprehensive categorization of animal fears: predatory animals, fear-relevant animals, dry or non-slimy invertebrates, slimy or wet-looking animals, and farm animals.

Davey et al. (1998, 2003) differentiated between affective assessments of animals as fear relevant and disgust relevant, and argued that fear of high predatory animals is associated with harm and pain, whereas fear of low-predation animals is associated with contamination or disease. However, the acquisition of emotional responses to many species may also reflect on the culture in question; people are known to respond differently to the presence of different wildlife species due, for example, to their religion and other traditions (e.g., Gogoi, 2018). Also, differing perspectives between urban and rural populations have been identified (Johansson et al., 2016b). Sponarski et al. (2013), however, have argued that, in the United States, the population in rural communities nowadays is heterogeneous with regard to attitudes toward wildlife. In addition local (media) debate may matter (Hathaway et al., 2017; Arbieu et al., 2019).

Finally, personal factors may moderate approach-avoidance tendencies and other appraisals in an encounter with wildlife. These factors include age, gender, as well as an individual's personal emotional dispositions toward specific species (Jacobs et al., 2012; Jacobs and Vaske, 2019). Such dispositions imply that there is a basis for appraisal of a specific animal species caused by whether the animal is regarded as intrinsically pleasant (negative valence), intrinsically unpleasant (positive valence), or neutral by the individual. Moreover, interests in nature and wildlife, and experiences of negative impacts on human property and livelihood, may moderate response to wildlife, as seen in studies concerned with large carnivores (Sjölander-Lindqvist et al., 2015; Eklund et al., 2020), moose (Dressel et al., 2020), geese (Eriksson et al., 2020), and seals (Johansson and Waldo, 2020).

\section{Nature Experience and Restoration}

Although the literature gives substantial evidence of the restorative benefits of nature experience (e.g., Stevenson et al., 2018; Hartig, 2021), various studies indicate that "nature" does not unequivocally elicit the approach responses that would sustain a restorative process. In a review, Patuano (2020) points to a fear of wild nature as a constraint on benefits. Nature being perceived as something scary and disgusting is put forward as a major reason, including the presence of risks of encountering dangerous and/or unattractive animals, as well as allergies, poisoning, vector-borne diseases, and getting lost due to disorientation (e.g., Bixler and Floyd, 1997). In contrast to such findings from survey and interview data, a meta-analysis of experimental findings found that the effect of exposure to nature on positive affect did not differ depending on whether it was categorized as "wild" or not (McMahan and Estes, 2015). Drawing on restorative environments theory, one can argue that it is not the "wild" component of wildlife per se that matters. Rather, the presence and activity of the wildlife need to be considered in relation to the activity in which a person wishes to engage while in the natural setting. People ordinarily approach natural areas with a set of expectations, and they perceive the environment in ways aligned with the goals of those activities. Hence, with regard to restoration, the appraisal of the presence and activity of wildlife can vary greatly according to whether it matches with expectations about whether and how the activity should serve restoration.

Such considerations get addressed in theorizing about restorative environments, though not only with regard to the particularities of encounters with wildlife. Looking into the necessary features of theories about nature as a restorative environment opens for insight into the ambivalent implications of the "wild." As outlined by Hartig (2021), theories must address two basic requirements for restoration to occur in a given setting. First, the setting must permit restoration. When moving into it, the person gains distance from the various demands that depleted their adaptive resources and so caused the need for restoration, and while there the person does not face new demands of the same kind, which would only further tax the depleted pool of resources that need restoration. Second the setting should promote restoration by attracting and holding the person's attention in a way that no intrusive thoughts of the demands left behind occurs. In other words, the person engages with environment and thus prolongs the restorative process. This promise of positive engagement, and not only the absence of negative features, underlies a basic definition of a "restorative environment" as one that promotes and not merely permits restoration (Hartig, 2017).

Two well-known theories about restorative environments address these requirements in ways that both contrast with and complement one another. These two theories - Stress Recovery Theory (Ulrich, 1983; Ulrich et al., 1991) and Attention Restoration Theory (Kaplan and Kaplan, 1989; Kaplan, 1995) have guided much of the research on how experiences in natural settings help to satisfy people's restoration needs. Stress Recovery Theory (SRT) is concerned with recovery from psychophysiological stress, an aversive condition manifest in heightened physiological arousal and negative emotions that can be adaptive in the short term but harmful for health and wellbeing when it persists. SRT asserts that immediate, pre-conscious affective responses to what one sees in the environment can influence attention, physiology and behavior, both mobilizing and giving coarse direction for adaptive action (i.e., to fight or flee) (Ulrich, 1983). Behind this assertion is the view that humans are innately attuned to certain environmental features that would have had adaptive significance during evolution, and that the perception of such features can very rapidly and effectively elicit like-dislike feelings and motivate approach-avoidance behaviors appropriate to continued well-being (Ulrich, 1983, 1993). In terms of SRT, a setting would permit restoration if there were an absence of perceived threats, and it would promote restoration if it had natural contents that drew non-vigilant attention, like the presence of water, that signaled enhanced possibilities 
for survival, as well visual scene characteristics such moderate complexity, gross structure, moderate depth, and the presence of a focal point. By evoking positive affect and holding nonvigilant attention, these features as perceived in the setting would block negative affect and negative thoughts, thus promoting physiological deactivation and so helping to restore the person's readiness to mobilize for action when a new threat or challenge would arise. After the initial affective response, more deliberate cognitive elaboration on what the person sees or otherwise senses can draw on different sources of experience (cultural and personal) in shaping the further course of stress recovery. Ulrich (1983) recognizes the relevance of both the immediate presence of wildlife (which may or may not be appraised as threatening) and inferences that could be drawn about their possible presence on the basis of visual characteristics of the given setting (e.g., high complexity, lack of gross structure, and lack of depth as characteristic of dense vegetation in which an animal might hide).

Attention Restoration Theory (ART; Kaplan, 1995) emphasizes cognitive functioning relevant to a person's ability to perform the kind of mental work so frequently called on in modern life. ART is concerned with recovery from directed attention fatigue, a condition seen to arise when a person must wilfully direct attention to a task that of itself lacks interest. To perform the task, the person must inhibit more interesting stimuli and thoughts that compete with the task for attention. Directing attention thus requires inhibitory effort, and this effort cannot be sustained indefinitely. When a person cannot sustain the effort any longer, and suffers from directed attention fatigue, recovery can occur when they can enter a situation in which attention can go freely and without effort to what they find interesting. In other words, while in the setting they can rely on what (Kaplan, 1978; Kaplan and Kaplan, 1989) refer to as fascination. Toward permitting and promoting the free play of restorative fascination, ART specifies the importance of compatibility between what the activities a person wants to do, can do, and must do in the situation. ART further specifies a sense of being away, or a change away from the routine mental contents with which one has been preoccupied; put simply, psychological distance from the conditions in which the need for restoration arose. The setting need not be novel or geographically distant for the person to gain this sense of being away. A fourth component of the restorative experience specified by ART involves the scope and coherence perceived in the setting, together opening for a sense of extent, relevant to the person's possibility for sustaining fascination and maintaining orientation while moving through the setting. Of the four experiential components described in ART, fascination stands as the key promoter of restoration, and particularly fascination of moderate intensity as it is engaged by unthreatening, aesthetically pleasing aspects of the setting (i.e., "soft" fascination). Kaplan and Kaplan emphasize that the natural environment is well-endowed with possibilities for fascination to become engaged, as when watching clouds, trees, sunsets, or running water or when exploring the surroundings. The presence of wild animals is pointed out as fascinating, though if they present a threat then they may evoke only a "hard" fascination that the Kaplans regard as less conducive to restoration because it does not leave mental room for thinking about other things (cf. the discussion of the alternation between soft fascination and mind wandering that can occur during a nature experience; Williams et al., 2018).

Arguably, of the two theories, ART treats in greater detail the preconditions that permit restoration in addition to an absence of threat - that is, matters of being away and compatibility- while SRT treats in greater detail the kind of on-going appraisal of the setting in terms relevant to the continuation of the restorative process while there, including but not limited to matters of threat. With regard to our consideration of how the presence and activity of wildlife bear on harm and restoration, we note that compatibility will typically come into the picture in the first stage of the restorative process, when choosing a suitable setting before a visit, and that possibilities for being away will figure in the assessment of compatibility. As noted earlier, however, we focus here on what happens during the second stage, while one or more people are engaged with the natural setting. We do so for two reasons. First, what happens on-site has implications not only for the restoration realized, but also for the recollection of the experience, and in turn choices of suitable settings for possible subsequent visits. Second, although acknowledged in SRT and ART, research guided by those theories has paid relatively little attention to wildlife as dynamic, animate components of natural environments that may appear and disappear at different times in the course of a visit to a natural setting, possibly promoting positive engagement but also possibly evoking a sense of threat and otherwise causing harm. Given this focus, our representation of the process will in important respects appear to align more closely with the description of stress recovery given by Ulrich in SRT. However, we do not mean to imply that our description has no relevance for the eventual restoration of directed attention capacity. A person may suffer both from stress and mental fatigue, and processes of recovery from the two conditions may unfold simultaneously (Hartig et al., 2003).

Neither SRT nor ART addresses in great detail the implications of the immediate social context of the visit to the natural setting. Yet, like the search for restoration, being in the company of family and friends has long stood out as a key motive for recreational visits to natural areas (e.g., Knopf, 1987; Manfredo et al., 1996). Moreover, the two motives will ordinarily work together, with a view to issues of both safety and mutual enjoyment (e.g., Staats and Hartig, 2004; Hartig, 2021). Having the company of some other(s) has particular relevance here in that it can influence the appraisal of wildlife that a person may encounter. A person may feel intense fear if meeting a wolf in a forest while alone or with a small child (Frank et al., 2015), but that person may feel quite secure and thrill at the shared experience if in the company of other adults.

\section{Appraisal Theory of Emotion and the Component Process Model}

As a final component of our specific theoretical background, an appraisal theory of emotion (Leventhal and Scherer, 1987; Scherer, 2001) leads us to postulate that appraisals of wildlife species differ not only between individuals, natural settings and 
social situation but also across and within specific situations. This theory thereby sheds light on how appraisals vary over time in ways not explicitly accounted for by SRT and ART. According to this theory, multiple appraisal processes directed toward a given set of stimuli may alternately elicit approach and avoidance responses that guide the individual's transaction with the environment. Because some appraisals are assumed to occur on a more or less automatic basis, demanding no or little mental resources, the multiple appraisal processes could conceivably run in parallel, but with different levels of intensity at different times. For one and the same animal, then, at a very basic level of processing, a person could be expected to respond more or less automatically to traits such as its taxa and size. At a more elaborated level of appraisal, the person's response would also involve interpretation of the animal in relation to the context (Kappas, 2006). Looking at approach and avoidance from an appraisal perspective implies that multiple types and levels of appraisals can occur in tandem or in a sequence, weighing approach against avoidance as the adaptive response.

In the appraisals initiated with the presence of an animal of a certain species, some appraisals occur at a sensory motor level much as inborn reflex-like responses (Leventhal and Scherer, 1987). For example, Walther (1969) showed that the size, direction, and speed of an approaching object did matter to a gazelle herds' fear responses of stuttering and fleeing. These responses were reasonably elicited by sensory motor appraisals. Such automatic responses can be seen in other non-human species (e.g., birds; Bossema and Burgler, 1980), and presumably in humans. Leventhal and Scherer (1987) also describe schematic and conceptual levels of appraisals. The schematic level is concerned with appraisals based on previous learning experience and can become automatic and effortless much like sensory motor appraisals. The appraisal on the conceptual level demands more effortful cognitive processing.

The Component Process Model (CPM, e.g., Scherer, 2001) states that a stimulus or event evokes a sequence of four groups of appraisals, namely relevance, implication, coping, and normative significance. The relevance appraisals consider aspects such as the degree of novelty, intrinsic pleasantness, and goal relevance of the event. These appraisals are made based on the individual's emotional disposition toward the animal and previous experience, but they also relate to the speed of appearance, intensity, and closeness of the event, for which previous experience may have little or no consequence. Implication appraisals are concerned with causality, outcome probability, discrepancy from expectation, conduciveness and urgency. Thus, these appraisals consider whether the event is due to natural causes or if there was an intention behind the event, as well as the extent to which the event resulted in what was expected, the extent to which it demanded action, and whether action is urgently required. The coping appraisals are concerned with control, power and adjustment. That is, they consider the probability that the person has the power to control the potential problems that attend an event or can adapt to the new situation. The final group of appraisals in this sequential model, normative significance, concerns the compatibility of the stimulus or event with internal and external standards. That is, they consider how the event relates to what the person finds to be right or wrong in relation to their own internal norms and how the event compares to the believed social norm concerning the event.

\section{A THEORETICAL INTEGRATION: MULTIPLE APPRAISALS ON-SITE DURING A RESTORATIVE EXPERIENCE}

Appraisal theory of emotion asserts that several processes of approach and avoidance in response to an environmental stimulus, in our case the presence of an animal, may run in sequence and in parallel at different levels of cognitive elaboration, and that they may to affect one another. HEI as a general theory, and SRT and ART as specific theories, encourage the understanding that the restorative potential of a situation involving wildlife is not adequately represented in terms of a person's general appraisals (e.g., utility and fear) arising from transactions between the characteristics of the animal and the cultural and individual characteristics of the person. Rather, the restorative outcome of a wildlife encounter would depend on multiple processes of appraisal of the animal in the particular situation, taking into account the role the person adopts in the situation and the activity related to that role. The appraisal processes that run continuously during the encounter may moreover yield results that are congruent or competitive with the components of experience that permit and promote restoration. Thus, the dynamics of situation-specific processes, some automatic and others more deliberative, would shape the restorative outcome.

Features of the natural setting and the social situation would also figure in these appraisal processes during a wildlife encounter and so influence the restorative quality of the experience. The unfolding of the restorative process would depend on the extent of the natural setting, considered both in experiential terms as described in ART and also from an ecological perspective, as suitable habitat where wildlife could be present. The unfolding of the restorative process would also depend on how well the person could gain distance from daily demands in the setting. The presence of other people and who they are would also matter. For example, people in areas with large carnivores in self-reports states stronger fear of an encounter if they would be accompanied by a child (Frank et al., 2015; Johansson et al., 2019). In other word, features of the natural setting and of the social situation would have a moderating role in appraisals and avoidance-approach responses during an encounter. Appraisals and avoidance-approach responses will bear on the unfolding of restorative processes through their influence on permitting and promoting factors, as outlined in the following paragraphs and illustrated in Figure 2.

Put in terms of CPM, the relevance appraisal as it bears on the permission of restoration would, in line with both SRT and ART, involve attention to threat. The relevance appraisal of the animal would therefore include consideration of its taxon, specific features such as its size and present behavior (e.g., whether it is moving toward one), as well as comparisons with previous experiences of wildlife associated with threat and 


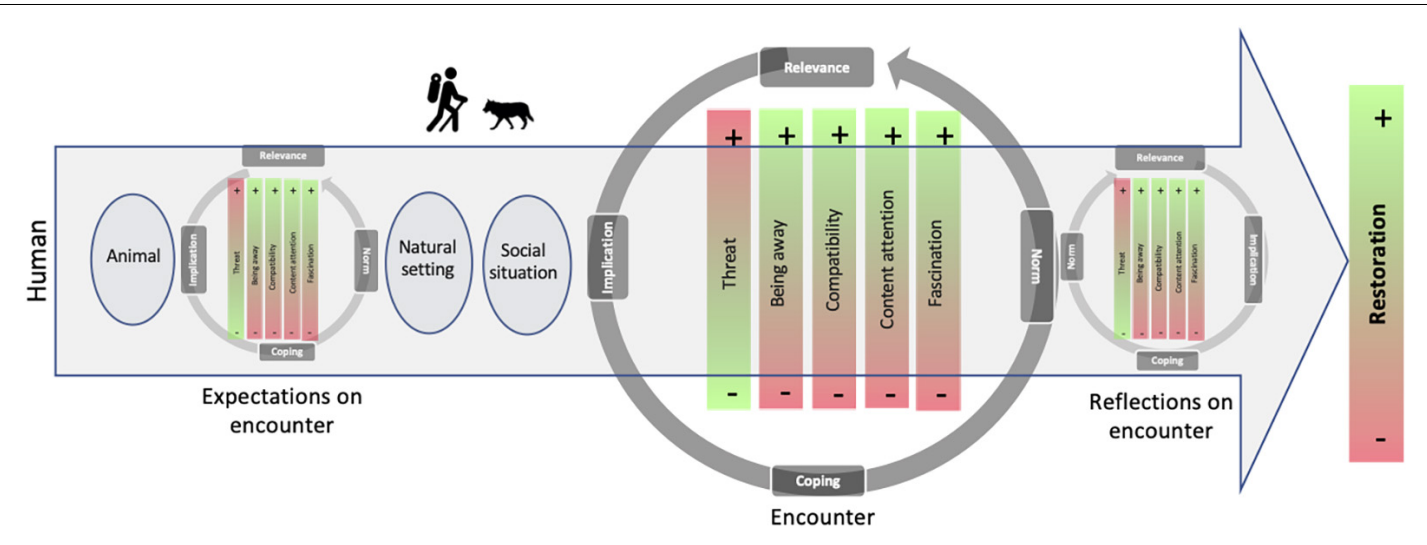

FIGURE 2 | A description of how an encounter with wildlife during a visit to a natural setting can lead to enhanced or reduced psychological restoration. Given the possibility of an encounter with a particular species of animal (shown with the silhouettes), expectations regarding the role of the encounter in the desired restorative experience will get shaped by general, cultural and personal appraisals of human-animal interactions, what is known of the natural setting and the social situation (e.g., whether one will be going alone or in the company of others). As with the formation of expectations, appraisals during the encounter concern matters of relevance, implications, coping potential, and norm congruence (Scherer, 2001) as related to components of restorative experience - threat, being away, compatibility, fascination and attention to content - described in attention restoration theory (Kaplan and Kaplan, 1989) and stress recovery theory (Ulrich, 1983). Subsequent reflection on the wildlife encounter would involve similar appraisals and shape the outcomes experienced after the visit as well as future expectations.

danger. These parameters could be expected to elicit sensory motor and schematic appraisal processes that build further on the same and perhaps additional animal characteristics (e.g., the speed at which it is moving toward one) as well as appraisals on a conceptual level that draw more deliberatively on cultural factors and personal experiences. It is likely that the sensory motor and schematic appraisals would dominate in the face of an imminently threatening animal, eliciting immediate avoidance responses that would interrupt restorative processes and induce stress. Appraisals on the conceptual level could also reduce the restorative potential of the setting if the person appraises the presence of an animal as somewhat threatening but cannot think about a way to cope that would be compatible with their personal norms. If the appearance of the animal would not be considered relevant as threatening or disgusting, or if the individual should find that they could cope with the situation, then the appraisal could instead result in an approach response.

Attention Restoration Theory stipulates another set of permitting factors on which appraisals of relevance would bear. These factors include the congruence of the presence of the animal with the perception of being away from the daily demands and the perceived compatibility with the activity in which the individual is engaged. These appraisals would mainly occur at the conceptual level, addressing relevance, potential implications, coping and the normative significance of further attending to the animal. If these appraisals would not be supportive of being away and/or compatibility, the animal encounter would likely result in neither avoidance nor approach, and thereby have little effect on the further course of the restorative process(es). But, if the appraisals would support perceptions of being away and compatibility, as with the appearance of a rare and sought-after bird in front of the bird watcher, the attention to the animal would elicit approach responses. This leads us to discuss how appraisals can bear on factors that promote restoration.
Stress Recovery Theory asserts that restoration is promoted by features of the setting that evoke positive affect and hold non-vigilant attention. These features could include how the animal fits into the configuration of space in the setting, a natural content that also enhances complexity and provides a distinct focal point. They could also be specific animal features, such as aesthetic traits of bio-behavioral similarity. ART asserts that restoration is promoted by soft fascination, enabled by a sense of being away and sustained by the perceived extent of the setting and compatibility in the activity there. Animals not being appraised in ways relevant to promoting factors would not receive further appraisals and have little impact on the further unfolding of restoration. However, if the person attends to the animal effortlessly, the implications of this fascination can then become a focus of appraisal: what will happen if staying in the situation watching the animal? If the individual finds the consequences may be negative and difficult to cope with, then there would be an avoidance response and the restorative process would not gain from further engagement with the animal. However, if the persons finds no negative consequences and/or is able to cope with remaining in the situation, then further approach responses would be possible. In this sequence, the implications of continued engagement presumably relate to being away and compatibility, as when the person breaks off engagement with the animal to turn back to the planned activity for which they have a limited amount of time. Even if the person finds that they could cope with the situation, however, continued engagement with the animal could violate personal or social norms, and so lead to avoidance and so an inability to realize the additional restorative value the encounter could provide were it to continue. For example, the bird watcher who sees the rare bird recognizes it is nesting, and that their presence is stressing the bird. Thus, the appraisal of a violation of norm congruence triggers an avoidance response that simultaneously interferes with the interconnected experiences of 
fascination, being away and compatibility, limiting the restorative value of the time in the setting.

\section{APPLYING THE MODEL WITH TWO SWEDISH WILDLIFE SPECIES}

In the Scandinavian countries, natural settings play an important role for consumptive as well as appreciative activities. About half of all Swedes have actively chosen to live close to nature, and in a national survey $80 \%$ of people reported that they spend leisure time in nature (Fredman et al., 2019). Sweden's area is dominated by boreal forest managed for logging purposes, for the most part highly accessible from main roads and forest roads (Zimmermann et al., 2014). Less than 5\% of the area of the country is covered by agricultural or urbanized land, and human density is often less than one person per $\mathrm{km}^{2}$ (Zimmermann et al., 2014). Even in the most densely populated areas in the southern parts of the country, natural settings are not far away, and many are accessible by regular public transport. Thus, much of Sweden's area serves as habitat for animals that people can encounter during recreational and other activities.

Clearly, Swedes do respond differently to different species. Based on factor analysis of national survey data, Johansson et al. (2012b) identified two main groups of animal fears. The first involved the four large carnivores found in Sweden (brown bear, wolf, lynx, and wolverine). The second involved fear of disgustrelevant animal species (tick, wasp, and snakes). Qualitative research in a Swedish context confirms that diverse native animal species such as moose, roe deer, wild boar, ticks and snakes become associated with threatening experiences, but for quite different reasons (e.g., fright, discomfort, destruction of property; Hagström, 2014). Geographical differences in people's experiences of the different animal species may influence feelings and attitudes toward them (Johansson et al., 2016b; Eriksson et al., 2020). The abundance of species such as wolves and wild boars provoke much debate in some areas, while other species, such as roe deer, may be of more limited concern and yet others, such as the squirrel, may pass with little comment. The discussion is primarily framed in terms of animal husbandry and hunting interests versus conservation interests in the case of wolves; of threats to agriculture in the case of wild boar; and of threats to forestry in the case of roe deer. From the general perspective of nature's contributions to people (Díaz et al., 2018), it would, however, also be relevant to illustrate the potential positive values of these species, as from a restoration perspective. Starting from our framework, we now outline different scenarios related to the play of restorative processes during an encounter with a wolf versus a roe deer while spending time in nature. We propose that each scenario should be analyzed in at least four aspects:

(1) Description of the animal in terms of the human-animal interaction;

(2) Contextual factors in terms of the natural setting and social situation;

(3) Appraisal of factors relevant for permitting restoration in the encounter situation;
(4) Appraisal of factors relevant for promoting restoration in the encounter situation.

These four aspects are treated sequentially in the sections to follow. In treating them, we also consider the appraisals of permitting and promoting factors at their different levels (sensory-motor, schematic, and conceptual). Furthermore, appraisals likely to occur at the conceptual level are further analyzed according to matters of relevance, implication, coping potential, and norm congruence.

\section{Aspect 1: Human - Animal Interaction}

Wolves (Canis lupus) belong to the taxa mammal, are relatively rare in Sweden, and have characteristics such as forward facing eyes (Supplementary Appendix 1). Considering these biological characteristics alone, one could expect that they would be rated high in preference and their presence would enhance the restorative potential of a natural setting. Considering the general human appraisal, however, wolves are perceived as a threatrelevant species that would diminish restorative potential.

Roe deer (Capreolus capreolus) also belong to the preferred taxa of mammals and have appreciated characteristics such as forward facing eyes. Even though they are relatively common, they would rate rather high in preference and enhance restorative potential (Supplementary Appendix 1). As for the general human appraisal, roe deer are not threat-relevant or disgustrelevant animals, so their presence would be unlikely to diminish restorative potential.

Taking a cultural perspective in brief, the wolf population in Sweden is closely monitored, and observations of wolves in shared landscapes rapidly get extensive media coverage. In contrast, the presence of roe deer usually passes unremarked. The presences of wolves causes long-running social conflicts between conservationists, hunters and farmers, among others, while roe deer typically do not arouse conflict. However, to understand appraisals of the two species, further information is needed about the person involved in the human-animal interaction. Consider, therefore, two people who are plausible in a Swedish cultural context:

- A woman of 70 years, with poor health, an emotional disposition of finding roe deer and other ungulates joyful to watch, living alone in a small house in a rural hamlet beside a natural setting (further described below). She keeps a few sheep in a nearby field as a hobby; she does not depend on them for income. She regularly goes berry-picking in the nearby natural setting.

- A man of 40 years, a forest-worker who lives with his wife and two small children in a house with a large garden on the outskirts of an urban area. The house is close to the natural setting.

The appraisals of the woman would likely reflect rural values commonly expressed in the debate about the large carnivores. As an animal owner, she would be highly aware of the threat of wolves to sheep, and due to her age and poor health she might also have concerns about her own vulnerability to those large carnivores. Her appraisals on encountering a wolf could 
therefore be expected to result in avoidance responses, potentially diminishing the restorative potential of an outing to the nearby natural setting should an encounter occur. Given her personal characteristics, values and interests, her appraisals of humananimal interactions involving roe deer would in contrast not diminish the restorative potential. However, as noted below, situation specific appraisals also need consideration.

The appraisals in a human-animal interaction involving a wolf would likely unfold differently for the middle-aged man. Identifying with urban values in the debate around large carnivores, he sees the wolf as important to conserve. $\mathrm{He}$ is accustomed to being in the forest and is confident that he could handle an encounter with a wolf, although he has never seen one in the wild. The presence of a wolf would not result in avoidance but rather interested observation which could contribute to restoration. As for the appraisal of human-animal interaction involving roe deer, he also appreciates roe deer as an important species in the local fauna, and he is used to seeing them while working in the forest. Roe deer do, however, frequently get into their garden to eat apples, which he finds a bit irritating. On the whole, the presence of a roe deer would not predictably elicit either an avoidance or approach response in a given encounter. Again, however, as noted below, situation specific appraisals need consideration.

This requires recognition that the sequential appraisals can be done in parallel at senso-motoric, schematic and conceptual levels, and that the differing pertinence of these appraisals can result in differences in the strength of avoidance - approach responses. Moreover, strong reactions as consequences of sensomotoric or schematic appraisals may override appraisals on the conceptual level. Thus, conceptual appraisals are more important when appraisals on the lower levels result in any valenced outcome.

\section{Aspect 2: Contextual Factors: The Natural Setting and Social Situation}

The natural setting our two people visit for restoration is a typical one in Sweden. It lies in a predominantly rural landscape with small hills of 50-100 m height. The vegetation consists of intensively managed forest dominated by Scots pine (Pinus sylvestris) and Norway spruce (Picea abies), with heather (Calluna vulgaris), grasses (Deschampsia spp.), and berry-producing shrubs (Vaccinium spp.) dominating the understory layer. This means the visibility is relatively low $(10-50 \mathrm{~m})$, and the light conditions are dusk-like even in sunny weather. The ground is dominated by different wet and soft mosses (Sphagnum spp.). Stones, fallen branches and trees make walking slow and running very difficult. The most commonly encountered vertebrates are small passerine birds. In addition to roe deer and wolves, mammal species include voles (Microtus spp.), moose (Alces alces), red fox (Vulpes vulpes), and lynx (Lynx lynx).

Walks and other recreational leisure activities in natural settings close to one's home are often made on a regular daily/weekly basis (Fredman et al., 2019), often together with family and friends but sometimes alone or in company of a family dog. For the social situation in the scenarios we have presented, if the person is not alone, then their company is likely to be close and familiar.

\section{Aspects 3 and 4: The Encounter Situation: Appraisals of Factors Permitting and Promoting Restoration}

Now, imagine that the woman, while standing in a forest glade appreciating the view, suddenly sees a wolf staring at her from a distance. There would first be appraisal at the senso-motoric level, resulting in a physiological response (e.g., increased heart beat). The schematic level of appraisal is then supposedly the strongest one, given that she finds herself and her sheep vulnerable to large carnivores. This means that appraisals on the conceptual level have no or limited impact. The appearance of the wolf is of high relevance as an intrinsically unpleasant experience to her, and it hinders pursuit of her goal of a restorative walk. The implication appraisal acknowledges the potential for injury. Given her age and poor health, she makes an appraisal of low coping potential. She might wish the wolf killed, but this is not congruent with her view (norm) on lethal management. On the whole, with these appraisals, the situation does not permit or promote restoration, and she returns home feeling more stressed than restored (Figure 3A).

If the woman would see a roe deer, we could expect the restorative process to unfold differently. There is no dominating senso-motoric response; rather, the encounter initiates appraisal on the schematic level, but it does not dominate the response as with the wolf. On the conceptual level, the encounter is appraised as having modest relevance, as it is of a kind that occurs with some frequency, but it is nonetheless a somewhat intrinsically pleasant experience and it doesn't interfere with her walk in the forest. Her implication appraisals refer to goal conduciveness, as seeing the roe deer is compatible with restoration sought with the forest walk. Most likely, appraisals of coping potential affirm a high level of control. The event thus permits restoration. Insofar as she stays in the moment, admiring the animal and following its behavior, the encounter promotes restoration, increasing a sense of being away and evoking soft fascination. She returns home more restored than usual; she does not always see such a beautiful animal on her walks in the setting (Figure 3B).

Consider now the man. He is standing in a glade in the forest, appreciating the view, when he sees a wolf staring at him from a distance. He appraises the presence of the wolf as relevant, as it is an unusual sight to him despite all the time he spends in the forest. His implication appraisals are done with regard to goal conduciveness, as the event promote the restorative quality of the forest walk. Considering his extensive forest experience, he appraises his coping potential as high. Thus, the event permits restoration, as there is no perceived threat. However, this might change if the social situation were different, and he was walking in the natural setting with his two small children. The sight of the wolf might then rapidly raise feelings of fear as he experiences more vulnerability. Just as in the previous case with the woman, this feeling would be elicited with senso-motoric and schematic appraisal processes. Subsequent appraisal of coping potential on a conceptual level could attenuate the fear response, and the 


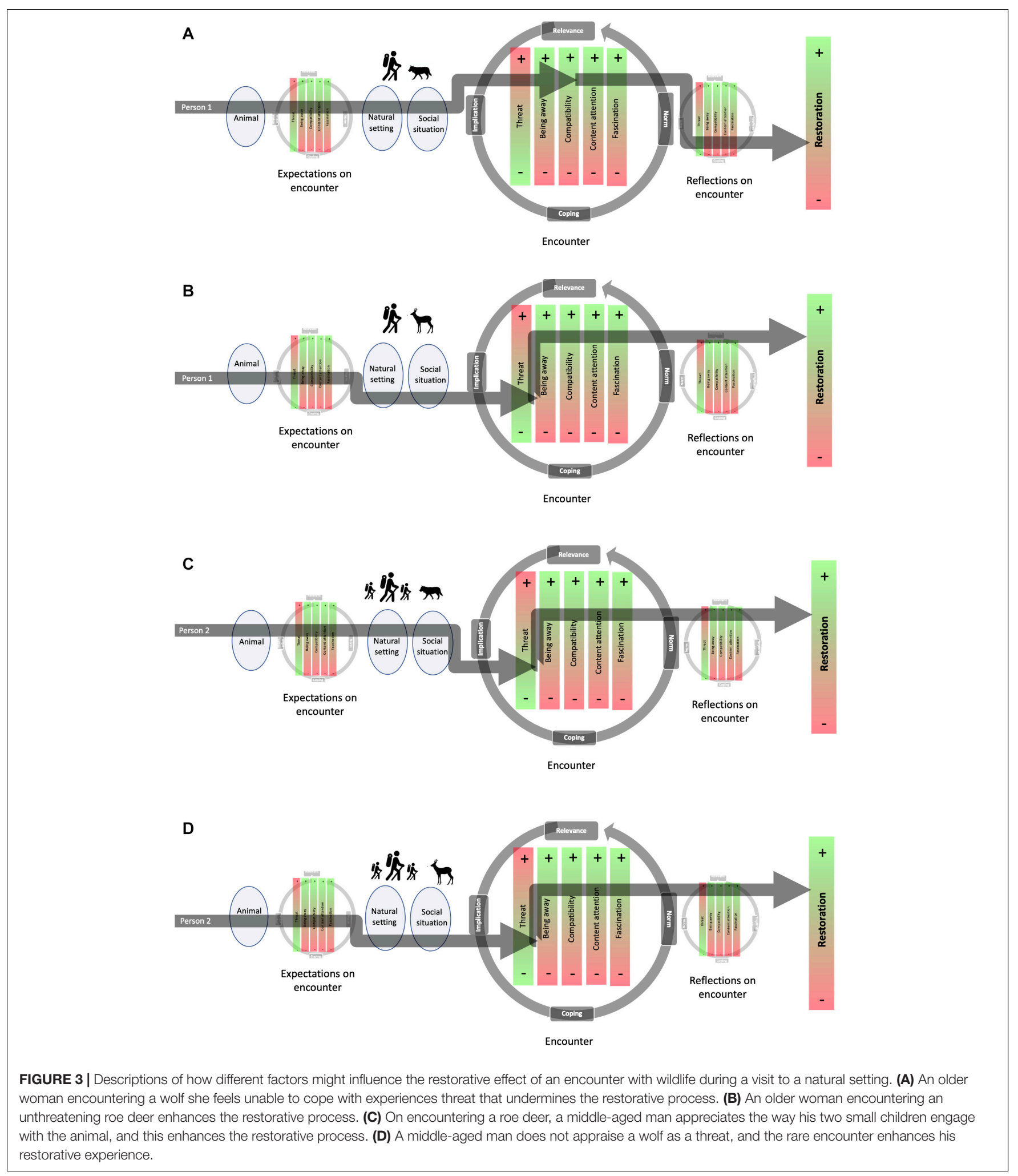

feeling of fear would then be overtaken by admiration of the animal permitting for restoration that might be amplified when safely shared with his children (Figure 3C). However, while alone he does not watch the wolf for long, as his attention is drawn to the new trees growing in the glade, something highly relevant to him because it reminds him of work he does in the forest. The appraisals necessary for the experience of being away are thus hindered, and the situation does not still fully 
permit restoration. Although encountering the wolf momentarily enhanced the restorative experience, that fleeting benefit has gotten offset by the reminders of work (cf., Von Lindern et al., 2013).

The outcome differs when the man is standing in the glade with his two small children, and they see a roe deer. The event does not at a schematic level elicit any feeling of fear or an avoidance response, and it thus permits the continuation of his restoration. However, at a conceptual level, seeing the roe deer elicits appraisals related to previous experiences of destroyed apple trees, and he disengages from the sight. The event is low on relevance, but it is for him somewhat intrinsically unpleasant, as the animal has negative implications for his gardening. He would, however, appraise his coping potential as high, and he sees that his children have made appraisals that manifest in expressions of curiosity and delight. There are no incentives for avoidance or approach on his part, but they remain watching the deer until the children take interest in something else. Although the intrinsic unpleasantness and negative implications of the roe deer are not compatible with restoration for him personally, he experiences being away and fascination as his children encounter the animal. An event that could result in stressful thoughts were he alone instead supports restoration in the company of his children (cf., Hartig, 2021) (Figure 3D).

\section{DISCUSSION}

This paper sheds light on some of the intangible aspects of nature's contributions to people. Referring to broad domains of adaptive pathways between wildlife and human health and well-being, we have considered how people's exposure to and experience with wildlife presence and activity can engage pathways in the domains of both restoring capacities and causing harm (cf. Marselle et al., 2021). Moreover we illustrate how this is likely to occur through parallel and partly overlapping appraisal processes, running from physiological to cognitively elaborated approach and avoidance responses (Leventhal and Scherer, 1987). Our framework and the accompanying process model thereby contribute to the literature by specifying potentially significant psychological processes running during encounters with wildlife. This makes it possible to gain further depth in the understanding of how people's personal experiences of nature matter to well-being outcomes. Our framework takes the perspective of the individual, and it draws inspiration from general theory on human-environment interaction and specific theory on emotional appraisal to integrate current views in the fields of human dimensions of wildlife and restorative environments. Our approach thus brings current discussions on nature and human health into alignment with discussions of the psychosocial consequences of wildlife conservation (e.g., Decker et al., 2012; Hartig et al., 2014).

With the integration of the two research fields we indicate that generalized appraisals concerning wildlife species and human interaction with these species affect the momentary appraisal processes during a specific encounter in a specific natural setting and consequently the restorative outcome of the visit to the setting. The core idea thus brought forward here is that the restorative value of natural settings can be expected to vary depending on the presence of wildlife, taking into account the ways in which people's appraisals can differ across species, physical and social environmental contexts, and specific situations. Moreover, the restoration outcome would depend on appraisals of a potential wildlife encounter before, during and after a nature visit. The framework thus offers new ways to consider the diversity of wildlife in terms of nature's contributions to people. The framework handles both the current negativity bias in the literature on human-wildlife relationships (Buijs and Jacobs, 2021) and the un-reflected view of nature as something unequivocally positive in much of the literature on the restorative aspects of nature.

Although we assume continuously ongoing appraisal processes, with our framework we propose that the analysis of appraisals during a nature visit ought to first attend to several aspects of the total situation. First among these is the human-animal interaction as it involves animal characteristics, general human appraisals, and cultural and individual factors. Such a description relies on results of research on human dimensions of wildlife and aids understanding of whether an encounter with the animal species in question is more likely to elicit approach or avoidance. The individual's emotional disposition toward an animal would be one factor moderating the relevance appraisal of intrinsic pleasantness of an encounter with the animal.

Second, contextual factors of the nature visit should be investigated including the natural setting and the social situation, as suggested by general theory concerned with humanenvironment interactions (the HEI model; Küller, 1991). As for the natural setting, the physical features and their configuration should be considered. One feature would be the spatial extent, another the density of the vegetation. The perception of such features could say something about how well a natural setting regardless of presence or absence of animal species might provide for restorative experiences (Kaplan and Kaplan, 1989), including perceived prospect and refuge known to play into the perceived safety (Gatersleben and Andrews, 2013). The social situation holds similar importance, as the appraisal of an animal encounter can go in different directions depending on whether, for example, an accompanying person would reinforce or mitigate threat responses (Frank et al., 2015; Hartig, 2021).

Further, appraisals of factors permitting and promoting restoration should be taken into account. Our process model aligns with the claim of conventional restorative environments theory that threatening wildlife will result in avoidance and constrained restoration, if not elevated stress (Ulrich, 1983). If the encounter is experienced as safe, it may promote restoration, especially if the encounter is also compatible with intended activity, strengthens the experience of being away, and evokes fascination. The encounter could thus deepen the engagement with the natural setting, sustaining restoration. The model also acknowledges that appraisals at different levels of cognitive elaboration in parallel and in sequence result in approach/avoidance responses that feed into the restorative process. Thus, the extent to which the combined critical appraisal 
parameters permit and promote restoration shapes the restorative outcome of a wildlife encounter during a visit to a natural setting.

The CPM (e.g., Scherer, 2001) offers a means to systematically describe the processing of the critical appraisal parameters, as shown in the scenarios examples given above. The usefulness of this model has previously been demonstrated in research on people's emotional responses toward diverse wildlife species (e.g., Eklund et al., 2020; Johansson et al., 2020). This earlier research shows that the appraisals of coping potential in relation to an encounter situation would be of particular significance for regulating fear responses. The predictability of animal behavior and controllability of one's own reaction in an encounter situation seem especially important (e.g., Johansson et al., 2019). In our examples, the focus was on the persons' appraisal processes, and animal behavior was kept constant. This may not be the case in a real encounter situation, and variation of animal behavior should be considered, especially concerning their gaze and speed and direction of movement, as these are characteristics likely to inform relevance appraisals (Scherer, 2001).

Considering that restoration includes appraisal processes before (expectations), during (experience), and after a visit (reflections), it could be expected that coping potential would have a critical role in the feedback loop from reflections on previous nature visits to planning and expectations for future visits. Since our application of the framework and process model here has focused upon the experience during a visit, we have not discussed this loop in detail. We think, though, that the coping appraisal would also be central to it. From a human health and well-being perspective it would be valuable to further study those situations where restoration is hindered or even counteracted to understand how people cope with such situations and potentially re-appraise the value of a particular natural setting.

We see possibilities for further informing these matters of process and outcomes through reference to other research and theory. We have chosen not to invoke here the extensive research on responses to snakes and spiders in animal phobia (e.g., Öhman et al., 2001), as phobic responses may reflect biologically prepared learning that follows elicitation patterns different from those seen with fear for other animals (Seligman, 1971). That is, in terms of emotional dispositions regarding intrinsic unpleasantness (Jacobs et al., 2012; Jacobs and Vaske, 2019), biologically based fear dispositions occupy a different category than dispositions for other stimuli. More attention is also needed with regard to the interpersonal processes in animal encounter situations where a person is in the company of other people. As illustrated in our scenario with the man and the child, company might affect the coping potential and the extent to which the encounter promotes restoration of one person through participation in another's experience. This aspect could be further analyzed by means of relational restoration theory (Hartig, 2021).

The next step then is to empirically test the framework and process model. In this, transdisciplinary collaboration will help to ensure high quality descriptions of natural settings and wildlife species, appropriate use of psychological theory and methodology, and involvement of policy-makers. Insights in wildlife policy, management and conservation status will guide choices among the most relevant wildlife species in various natural settings of concern. From a methodological perspective, triangulation is called for. A first step would be to systematically collect qualitative information about different people's personal experiences of wildlife during their visits to natural settings for psychological restoration. Cross-sectional studies could test the validity of the framework in both urban and rural contexts, and among different groups. In line with considerations of nature's contribution to people and the call for integrating local knowledge, we illustrated the application of the framework with examples of people seeking restorative experiences in their local nature settings. The proposed integration of psychological processes is, however, generic; it can also be used to understand how wildlife figures in restorative outcomes among nature tourists and others. Knowledge about the appraisal processes and their relative importance for the restorative outcome could be experimentally tested, in simulated as well as real settings. Mobile methods including both psychophysiological measures and self-reports would be useful in this (Flykt et al., 2013).

\section{CONCLUSION AND IMPLICATIONS}

Wildlife conservation and management need to go hand-in-hand with efforts to support human health and well-being; from the perspective of policy-making, a One Health approach is needed ${ }^{2}$. In this case, it means that concerns related to public health must be integrated with nature conservation, considering not only the prevention of disease in humans and protection of animal populations but also the building of capacities that depend on co-existence, including ethical sensibilities regarding the rights of other species to exist and thrive (Leopold, 1970; Moline, 1986). This is not easy task, but here we show one way forward by describing the role that wildlife encounters can play in restorative experiences, thus opening for new ideas and bridges to other fields. For example, reliance on nature for restorative experiences seems to promote environmental concern and a broad range of pro-environmental behaviors (Hartig et al., 2007).

In recent years, wildlife management plans in Sweden and elsewhere have acknowledged people's fear of large carnivores to overcome impact and social conflicts. Psycho-social stress caused by certain species has also been referred to lately (Nordström, 2010; Zahl-Thanem et al., 2020). We think that additional psychological perspectives could enlighten the current debate on wildlife and wildlife management. The understanding of the role of wildlife in restorative processes strengthens a more integrated approach to wildlife conservation, and constitutes a salutogenic stance for policy discussions and social conflicts over wildlife (see also Buijs and Jacobs, 2021).

Our paper points to the need to better understand humananimal interactions, their contextualization in terms of the features of the natural setting and social situations, and the individual's appraisals of relevance, implications, coping potential and norm congruence as they relate to the permission and promotion of restoration. Furthermore, our approach offers concepts associated with established instruments for evaluating

\footnotetext{
${ }^{2}$ https://www.who.int/news-room/q-a-detail/one-health
} 
outcomes of transformative changes to current approaches to nature conservation and wildlife management, required to achieve sustainable use of natural settings. Attention to these psychological processes opens for a more informed dialog about wildlife by accounting for people's experiences in a more systematic way. The proposed framework and process model can thus support bottom-up processes contributing to local nature conservation and management in relation to restorative opportunities.

\section{DATA AVAILABILITY STATEMENT}

The original contributions generated for this study are included in the article/Supplementary Material, further inquiries can be directed to the corresponding author.

\section{AUTHOR CONTRIBUTIONS}

All authors have contributed to funding acquisition and development of the theoretical framework presented here. MJ

\section{REFERENCES}

Apollonio, M., Andersen, R., and Putman, R. (Eds). (2010). "Present status and future challenges for European ungulate management," in European Ungulates and Their Management in the 21st Century, (Cambridge: Cambridge University Press), 578-604.

Arbieu, U., Mehring, M., Bunnefeld, N., Kaczensky, P., Reinhardt, I., Ansorge, H., et al. (2019). Attitudes towards returning wolves (Canis lupus) in Germany: exposure, information sources and trust matter. Biol. Conserv. 234, 202-210. doi: 10.1016/j.biocon.2019.03.027

Arrindell, W. A. (2000). Phobic dimensions: IV. The structure of animal fears. Behav. Res. Ther. 38, 509-530. doi: 10.1016/s0005-7967(99)00097-2

Batt, S. (2009). Human attitudes towards animals in relation to species similarity to humans: a multivariate approach. Biosci. Horiz. 2, 180-190. doi: 10.1093/ biohorizons/hzp021

Bixler, R. D., and Floyd, M. F. (1997). Nature is scary, disgusting, and uncomfortable. Environ. Behav. 29, 443-467. doi: 10.1177/ 001391659702900401

Bossema, I., and Burgler, R. R. (1980). Communication during monocular and binocular looking in European jays. Behaviour 74, 274-283. doi: 10.1163/ 156853980x00492

Bratman, G. N., Anderson, C., Berman, M. G., Cochran, B., de Vries, S., Flanders, J., et al. (2019). Nature and mental health: an ecosystem service perspective. Sci. Adv. 5:eaax0903.

Buijs, A., and Jacobs, M. (2021). Avoiding negativity bias: towards a positive psychology of human-wildlife relationships. Ambio 50, 281-288. doi: 10.1007/ s13280-020-01394-w

Cameron, R. W. F., Brindley, P., Mears, M., McEwan, K., Ferguson, F., Sheffield, D., et al. (2020). Where the wild things are! Do urban green spaces with greater avian biodiversity promote more positive emotions in humans? Urban Ecosyst. 23, 301-317. doi: 10.1007/s11252-020-00929-z

Carver, C. S. (2006). Approach, avoidance, and the self-regulation of affect and action. Motiv. Emot. 30, 105-110. doi: 10.1007/s11031-006-9044-7

Chapron, G., Kaczensky, P., Linnell, J. D. C., von Arx, M., Huber, D., Andrén, H., et al. (2014). Recovery of large carnivores in Europe's modern humandominated landscapes. Science 346, 1517-1519.

Corr, P. J. (2013). Approach and avoidance behaviour: multiple systems and their interactions. Emot. Rev. 5, 285-290. doi: 10.1177/1754073913477507

Davey, G. C. L., Cavanagh, K., and Lamb, A. (2003). Differential aversive outcome expectancies for high- and low-predation fear relevant animals. J. Behav. Ther. Exp. Psychiatry 34, 117-128. doi: 10.1016/s0005-7916(03)00024-7 drafted the manuscript, with substantial inputs of text, graphic representations, and critical commentary from AF, JF, and TH. All authors revised the text.

\section{FUNDING}

The participation of all four authors was supported by a grant from the Swedish Research Council for Environment, Agricultural Sciences and Spatial Planning (FORMAS) ("Wolves, wild boar and other wildlife: Cultural ecosystem services and disservices for outdoor recreation and human wellbeing"; grant nr. 2016-01157; principal investigator, Maria Johansson, Lund University).

\section{SUPPLEMENTARY MATERIAL}

The Supplementary Material for this article can be found online at: https://www.frontiersin.org/articles/10.3389/fenvs. 2021.635757/full\#supplementary-material

Davey, G. C. L., McDonald, A. S., Hirisame, U., Prabhu, G. G., Iwawaki, S., Jim, C. I., et al. (1998). A cross-cultural study of animal fears. Behav. Res. Ther. 36, 735-750. doi: 10.1016/s0005-7967(98)00059-x

Decker, D. J., Riley, S. J., and Siemer, W. F. E. (2012). Human Dimensions of Wildlife Management, 2nd Edn. Baltimore, MD: Johns Hopkins University Press.

Díaz, S., Pascual, U., Stenseke, M., Martín-López, B., Watson, R. T., Molnár, Z., et al. (2018). Assessing nature's contribution to people. Science 359, 270-272.

Dressel, S., Johansson, M., Ericsson, G., and Sandström, C. (2020). Perceived adaptive capacity within a multi-level governance setting: the role of bonding, bridging, and linking social capital. Environ. Sci. Policy 04, 88-97. doi: 10.1016/ j.envsci.2019.11.011

Dzhambov, A., Hartig, T., Markevych, I., Tilov, B., and Dimitrova, D. (2018). Urban residential greenspace and mental health in youth: different approaches to testing multiple pathways yield different conclusions. Environ. Res. 160, 47-59. doi: 10.1016/j.envres.2017.09.015

Eklund, A., Flykt, A., Frank, J., and Johansson, M. (2020). Animal owners' appraisal of large carnivore presence and use of interventions to prevent carnivore attacks on domestic animals in Sweden. Eur. J. Wildl. Res. 66:31.

Elliot, A. J., Eder, A. B., and Harmon-Jones, E. (2013). Approach-avoidance motivation and emotion: convergence and divergence. Emot. Rev. 5, 308-311. doi: 10.1177/1754073913477517

Eriksson, L., Johansson, M., Månsson, J., Redpath, S., Sandström, C., and Elmberg, J. (2020). The public and geese: a conflict on the rise? Hum. Dimens. Wildl. 25, 1-17. doi: 10.1080/10871209.2020.1752420

Fischer, A., Bednar-Friedl, B., Langers, F., Dobrovodská, M., Geamana, N., Skogen, K., et al. (2011). Universal criteria for species conservation priorities? Findings from a survey of public views across Europe. Biol. Conserv. 144, 998-1007. doi: 10.1016/j.biocon.2010.12.004

Flykt, A., Johansson, M., Karlsson, J., Lindeberg, S., and Lipp, O. (2013). Fear of wolf and bear. Hum. Dimens. Wildl. 18, 416-443.

Frank, J., Johansson, M., and Flykt, A. (2015). Public attitude towards the implementation of management actions aimed at reducing human fear of brown bears and wolves. Wildl. Biol. 21, 122-130. doi: 10.2981/wlb.13116

Fransson, U., and Hartig, T. (2010). Leisure home ownership and early death: a longitudinal study in Sweden. Health Place 16, 71-78. doi: 10.1016/j. healthplace.2009.08.005

Fredman, P., Ankre, R., and Chekalina, T. (2019). Friluftsliv 2018. Report 6687. Stockholm: Naturvårdsverket.

Fuller, R. A., Irvine, K. N., Devine-Wright, P., Warren, P. H., and Gaston, K. J. (2007). Psychological benefits of greenspace increase with biodiversity. Biol. Lett. 3, 390-394. doi: 10.1098/rsbl.2007.0149 
Gatersleben, B., and Andrews, M. (2013). When walking in nature is not restorative-the role of prospect and refuge. Health Place 20, 91-101. doi: 10.1016/j.healthplace.2013.01.001

Gogoi, M. (2018). Emotional coping among communities affected by wildlifecaused damage in north-east India: opportunities for building tolerance and improving conservation outcomes. Oryx 5, 214-219. doi: 10.1017/ s0030605317001193

Gray, J. A. (1982). The Neuropsychology of Anxiety: An Enquiry into the Functions of the Septo-Hippocampal System. Oxford: Oxford University Press.

Hagström, C. (2014). “Otäcka djur och tråkig natur," in Naturen För Mig: Nutida Röster och Kulturella Perspektiv, eds L. Midholm and K. Saltzman (Uppsala: Institutet för språk och folkminnen), 47-56.

Hartig, T. (2017). "Restorative environments," in Reference Module in Neuroscience and Biobehavioral Psychology, ed. J. Stein (Oxford: Elsevier), 1-9.

Hartig, T. (2021). "Restoration in nature: beyond the conventional narrative," in Nature and Psychology: Biological, Cognitive, Developmental, and Social Pathways to Well-Being (Proceedings of the 67th Annual Nebraska Symposium on Motivation) (pp. in press), eds A. Schutte, J. Torquati, and J. Stevens (Cham: Springer Nature). doi: 10.3368/er.23.1.1

Hartig, T., Evans, G. W., Jamner, L. D., Davis, D. S., and Gärling, T. (2003). Tracking restoration in natural and urban field settings. J. Environ. Psychol. 23, 109-123. doi: 10.1016/s0272-4944(02)00109-3

Hartig, T., Kaiser, F. G., and Strumse, E. (2007). Psychological restoration in nature as a source of motivation for ecological behavior. Environ. Conserv. 34, 291-299.

Hartig, T., Mitchell, R., de Vries, S., and Frumkin, H. (2014). Nature and health. Annu. Rev. Public Health 35, 207-228.

Hartig, T., van den Berg, A., Hagerhall, C., Tomalak, M., Bauer, N., Hansmann, R., et al. (2011). "Health benefits of nature experience: psychological, social and cultural processes," in Forests, Trees, and Human Health, eds K. Nilsson, M. Sangster, C. Gallis, T. Hartig, S. De Vries, K. Seeland, et al. (Dordrecht: Springer), 127-168. doi: 10.1007/978-90-481-9806-1_5

Hathaway, S. R., Bryant, M. A. E., Draheim, M. M., Vinod, P., Limaye, S., and Athreya, V. (2017). From Fear to understanding: changes in media representations of leopard incidences after media awareness workshops in Mumbai, India. J. Urban Ecol. 3, 1-7.

Home, R., Hunziker, M., and Bauer, N. (2012). Psychosocial outcomes as motivations for visiting nearby urban green spaces. Leis. Sci. 34, 350-365. doi: 10.1080/01490400.2012.687644

Jacobs, M. H., Vaske, J. J., and Roemer, J. M. (2012). Toward a mental systems approach to human relationships with wildlife: the role of emotional dispositions. Hum. Dimens. Wildl. 17, 4-15. doi: 10.1080/10871209.2012. 645123

Jacobs, M., and Vaske, J. J. (2019). "Understanding emotions as opportunities for and barriers to coexistence with wildlife," in Human-Wildlife Interactions: Turning Conflict into Coexistence, eds B. Frank, J. Glikman, and S. Marchini (Cambridge: Cambridge University Press), 65-84. doi: 10.1017/9781108235730. 007

Jacobs, M., Vaske, J. J., Dubois, S., and Fehres, P. (2014). More than fear: role of emotions in acceptability of lethal control of wolves. Eur. J. Wildl. Res. 60, 589-598. doi: 10.1007/s10344-014-0823-2

Johansson, M., and Waldo, $\AA$ (2020). Local people's appraisal of the fishery-seal situation in traditional fishing villages on the Baltic Sea Coast in Southeast Sweden. Soc. Nat. Resour. 34, 271-290. doi: 10.1080/08941920.2020.1809756

Johansson, M., Ferreira, I., Støen, O.-G., Frank, J., and Flykt, A. (2016a). Targeting human fear of large carnivores - many ideas but few known effects. Biol. Conserv. 20, 261-269. doi: 10.1016/j.biocon.2016.07.010

Johansson, M., Flykt, A., Frank, J., and Støen, O.-G. (2019). Controlled exposure reduces fear of brown bears. Hum. Dimens. Wildl. 24, 363-379. doi: 10.1080/ 10871209.2019.1616238

Johansson, M., Karlsson, J., Pedersen, E., and Flykt, A. (2012a). Factors governing human fear of brown bear and wolf. Hum. Dimens. Wildl. 17, 58-74. doi: 10.1080/10871209.2012.619001

Johansson, M., Mysterud, A., and Flykt, A. (2020). Livestock owners' worry and fear of tick-borne diseases. Parasit. Vectors 13:331.

Johansson, M., Sandström, C., Pedersen, E., and Ericsson, G. (2016b). Factors governing human fear of wolves: moderating effects of geographical location and standpoint on protected nature. Eur. J. Wildl. Res. 62, 749-760. doi: 10.1007/s10344-016-1054-5

Johansson, M., Sjostrom, M., Karlsson, J., and Brannlund, R. (2012b). Is human fear affecting public willingness to pay for the management and conservation of large carnivores? Soc. Nat. Resour. 25, 610-620. doi: 10.1080/08941920.2011. 622734

Jorgensen, A., and Gobster, P. H. (2010). Shades of green: measuring the ecology of urban green space in the context of human health and well-being. Nat. Cult. 5, 338-363. doi: $10.3167 /$ nc. 2010.050307

Jorgensen, A., Hitchmough, J., and Dunnett, N. (2007). Woodland as a setting for housing-appreciation and fear and the contribution to residential satisfaction and place identity in Warrington New Town, UK. Landsc. Urban Plan. 79, 283-287.

Kaplan, R., and Kaplan, S. (1989). The Experience Of Nature: A Psychological Perspective. New York: Cambridge University Press.

Kaplan, S. (1978). "Attention and fascination: the search for cognitive clarity," in Humanscape: Environments for People, eds S. Kaplan and R. Kaplan (Belmont, CA: Duxbury Press), 84-90. (Reissued in 1982 by Ulrich's Books, Ann Arbor, Michigan).

Kaplan, S. (1995). The restorative benefits of nature: toward an integrative framework. J. Environ. Psychol. 15, 169-182. doi: 10.1016/0272-4944(95) 90001-2

Kappas, A. (2006). Appraisals are direct, immediate, intuitive, and unwitting and some are reflective. Cogn. Emot. 20, 952-975. doi: 10.1080/0269993060061 6080

Kellert, S. R. (1985). Public perceptions of predators, particularly the wolf and coyote. Biol. Conserv. 31, 167-189. doi: 10.1016/0006-3207(85)90047-3

Kelly, A. G., Slagle, K. M., Wilson, R. S., Moeller, S. J., and Bruskotter, J. T. (2016). Changes in attitudes toward animals in the United States from 1978-2014. Biol. Conserv. 201, 237-242. doi: 10.1016/j.biocon.2016.07.013

Knegtering, E., Hendrickx, L., van der Windt, H. J., and Schootuiterkamp, A. J. M. (2002). Effects of species characteristics on nongovernmental organizations' attitudes toward species conservation policy. Environ. Behav. 34, 378-400. doi: $10.1177 / 0013916502034003006$

Knight, A. J. (2008). Bats, snakes and spiders, Oh my! How aesthetic and negativistic attitudes and other concepts predict support for species protection. J. Environ. Psychol. 28, 94-103. doi: 10.1016/j.jenvp.2007.10.001

Knopf, R. C. (1987). "Human behavior, cognition and affect in the natural environment," in Handbook of Environmental Psychology, Vol. 1, eds D. Stokols and I. Altman (New York: Wiley), 783-825.

Kubo, T., and Shoji, Y. (2014). Trade-off between human-wildlife conflict risk and recreation conditions. Eur. J. Wildl. Res. 60, 501-510. doi: 10.1007/s10344-0140812-5

Küller, R. (1991). "Environmental assessment from a neuropsychological perspective," in Environment, Cognition and Action, eds T. Gärling and G. W. Evans (New York, NY: Oxford University Press), 111-147.

Leopold, A. (1970). A Sand County Almanac, with Essays on Conservation from Round River. New York: Sierra Club/Ballantine.

Leventhal, H., and Scherer, K. (1987). The relationship of emotion to cognition: a functional approach to semantic controversy. Cogn. Emot. 1, 3-28. doi: $10.1080 / 02699938708408361$

Manesi, Z., Van Lange, P., and Pollet, T. V. (2015). Butterfly eyespots: their potential influence on aesthetic preferences and conservation attitude. PLoS One 10:e0141433. doi: 10.1371/journal.pone.0141433

Manfredo, M. J. (2008). Who Cares About Wildlife? Social Science Concepts for Exploring Human-Wildlife Relationships and Conservation Issues. New York, NY: Springer.

Manfredo, M. J., Driver, B. L., and Tarrant, M. A. (1996). Measuring leisure motivation: a meta-analysis of the recreation experience preference scales. J. Leis. Res. 28, 188-213. doi: 10.1080/00222216.1996.11949770

Markevych, I., Schoierer, J., Hartig, T., Chudnovsky, A., Hystad, P., Dzhambov, A. M., et al. (2017). Exploring pathways linking greenspace to health: theoretical and methodological guidance. Environ. Res. 158, 301-317. doi: 10.1016/j. envres.2017.06.028

Marselle, M. R., Hartig, T., Cox, D. T. C., de Bell, S., Knapp, S., Lindley, S., et al. (2021). Pathways linking biodiversity to human health: a conceptual framework. Environ. Int. 150:106420. 
McMahan, E. A., and Estes, D. (2015). The effect of contact with natural environments on positive and negative affect: a meta-analysis. J. Posit. Psychol. 10, 507-519. doi: 10.1080/17439760.2014.994224

Methorst, J., Arbieu, U., Bonn, A., Böhning-Gaese, K., and Müller, T. (2020). Nonmaterial contributions of wildlife to human-wellbeing: a systematic review. Environ. Res. Lett. 15:093005. doi: 10.1088/1748-9326/ab9927

Moline, J. N. (1986). Aldo Leopold and the moral community. Environ. Ethics 8, 99-120. doi: 10.5840/enviroethics19868222

Nordström, A. (2010). Upplevelser av Boendemiljö och Psykisk Hälsa hos Boende $i$ Områden med Förekomst av Översvämningsmygg. MSc thesis. Uppsala: Department of Psychology, Uppsala University.

Öhman, A., Flykt, A., and Esteves, F. (2001). Emotion drives attention: detecting the snake in the grass. J. Exp. Psychol. Gen. 130, 466-478. doi: 10.1037/00963445.130.3.466

Pascual, U., Balvanera, P., Díaz, S., Pataki, G., Roth, E., Stenseke, M., et al. (2017). Valuing nature's contributions to people: the IPBES approach. Curr. Opin. Environ. Sustain. 26-27, 7-16.

Pătru-Stupariu, I., Andreea, N., Mihai, M., Huzui-Stoiculescu, A., and Fürst, C. (2020). Using social network methodological approach to better understand human-wildlife interactions. Land Use Policy 99:105009. doi: 10.1016/j. landusepol.2020.105009

Patuano, A. (2020). Biophobia and urban restorativeness. Sustainability 12:4312. doi: $10.3390 /$ su12104312

Penteriani, V., del Mar Delgado, M., Pinchera, F., Naves, J., Fernaìndez-Gil, A., Kojola, I., et al. (2016). Human behaviour can trigger large carnivore attacks in developed countries. Sci. Rep. 6:20552.

Pyle, R. M. (1993). The Thunder Tree: Lessons from An Urban Wildland. Boston, MA: Houghton Mifflin.

Redpath, S. M., Young, J., Evely, A., Adamas, W. M., Sutherland, W. J., Whitehouse, A., et al. (2013). Understanding and managing conservation conflicts. Trends Ecol. Evol. 28, 100-109.

Sahlén, V., Friebe, A., Saebo, S., Swenson, J. E., and Stoen, O.-G. (2015). Den entry behaviour in Scandinavian brown bears: implications for preventing human injuries. Wildl. Manag. 79, 274-287. doi: 10.1002/jwmg.822

Scherer, K. R. (2001). “Appraisal considered as a multi-level sequential checking," in Appraisal Processes in Emotion: Theory, Methods, Research, eds K. R. Scherer, A. Schorr, and T. Johnstone (New York: Oxford University Press), 92-120.

Seligman, M. E. P. (1971). Phobias and preparedness. Behav. Ther. 2, 307-321. doi: 10.1016/s0005-7894(71)80064-3

Serpell, J. A. (2004). Factors influencing human attitudes to animals and their welfare. Anim. Welf. 13, 145-151.

Sjölander-Lindqvist, A., Johansson, M., and Sandström, C. (2015). Individual and collective responses to large carnivore management: the roles of trust, representation, knowledge spheres, communication and leadership. Wildl. Biol. 21, 175-185. doi: 10.2981/wlb.00065

Slunge, D., and Boman, A. (2018). Learning to live with ticks? The role of exposure and risk perceptions in protective behaviour against tick-borne diseases. PLoS One 13:e0198286. doi: 10.1371/journal.pone.0198286

Smith, R. J., Verissimo, D., Isaac, N. J. B., and Jones, K. E. (2012). Identifying Cinderella species: uncovering mammals with conservation flagship appeal. Conserv. Lett. 5, 205-212. doi: 10.1111/j.1755-263x.2012. 00229.x

Soga, M., and Gaston, K. J. (2016). Extinction of experience: the loss of human-nature interactions. Front. Ecol. Environ. 14:94-101. doi: 10.1002/fee. 1225
Sponarski, C. C., Semeniuk, C., Glikman, J. A., Bath, J. A., and Musiani, M. (2013). Heterogeneity among rural resident attitudes toward wolves. Hum. Dimens. Wildl. 18, 239-248. doi: 10.1080/10871209.2013.792022

Staats, H., and Hartig, T. (2004). Alone or with a friend: a social context for psychological restoration and environmental preferences. J. Environ. Psychol. 24, 199-211. doi: 10.1016/j.jenvp.2003.12.005

Staats, H., Kieviet, A., and Hartig, T. (2003). Where to recover from attentional fatigue: an expectancy-value analysis of environmental preference. J. Environ. Psychol. 23, 147-157. doi: 10.1016/s0272-4944(02)00112-3

Stevenson, M. P., Schilhab, T., and Bentsen, P. (2018). Attention restoration theory II: a systematic review to clarify attention processes affected by exposure to natural environments. J. Toxicol. Environ. Health Part B 21, 227-268. doi: 10.1080/10937404.2018.1505571

Ulrich, R. S. (1983). "Aesthetic and affective response to natural environment," in Behavior and The Natural Environment, eds I. Altman and J. F. Wohlwill (New York: Plenum), 85-125. doi: 10.1007/978-1-4613-3539-9_4

Ulrich, R. S. (1993). "Biophilia, biophobia, and natural landscapes," in The Biophilia Hypothesis, eds S. R. Kellert and E. O. Wilson (Washington, DC: Island Press), 73-137.

Ulrich, R. S., Simons, R., Losito, B. D., Fiorito, E., Miles, M. A., and Zelson, M. (1991). Stress recovery during exposure to natural and urban environments. J. Environ. Psychol. 11, 201-230. doi: 10.1016/s0272-4944(05)80184-7

Velarde, M. D., Fry, G., and Tveit, M. (2007). Health effects of viewing landscapes landscape types in environmental psychology. Urban For. Urban Green. 6, 199-212. doi: 10.1016/j.ufug.2007.07.001

Von Lindern, E., Bauer, N., Frick, J., Hunziker, M., and Hartig, T. (2013). Occupational engagement as a constraint on restoration during leisure time in natural environments. Landsc. Urban Plan. 118, 90-97. doi: 10.1016/j. landurbplan.2013.03.001

Walther, F. R. (1969). Flight behaviour and avodiance of predators in Thomson's Gazelle. Behaviour 34, 184-221. doi: 10.1163/156853969x00053

Ware, J., Jain, K., Burgess, I., and Davey, G. C. L. (1994). Disease-avoidance model: factor analysis of common animal fears. Behav. Res. Ther. 1, 57-63. doi: 10.1016/0005-7967(94)90084-1

Williams, K. J. H., Lee, K. E., Hartig, T., Sargent, L. D., Williams, N. S., and Johnson, K. A. (2018). Conceptualising creativity benefits of nature experience: attention restoration and mind wandering as complementary processes. J. Environ. Psychol. 59, 36-45. doi: 10.1016/j.jenvp.2018.08.005

Zahl-Thanem, A., Burton, R. J. F., Blekesaune, A., Haugen, M. S., and Ronningen, K. (2020). The impact of wolves on psychological distress among farmers in Norway. J. Rural Stud. 78, 1-11. doi: 10.1016/j.jrurstud.2020.05.010

Zimmermann, B., Nelson, L., Wabakken, P., Sand, H., and Liberg, O. (2014). Behavioral responses of wolves to roads: scale-dependent ambivalence. Behav. Ecol. 25, 1353-1364. doi: 10.1093/beheco/aru134

Conflict of Interest: The authors declare that the research was conducted in the absence of any commercial or financial relationships that could be construed as a potential conflict of interest.

Copyright (c) 2021 Johansson, Flykt, Frank and Hartig. This is an open-access article distributed under the terms of the Creative Commons Attribution License (CC BY). The use, distribution or reproduction in other forums is permitted, provided the original author(s) and the copyright owner(s) are credited and that the original publication in this journal is cited, in accordance with accepted academic practice. No use, distribution or reproduction is permitted which does not comply with these terms. 